\title{
Stewart Bluefarb syndrome: case report of a rare variant of acroangiodermatitis
}

\section{Guneet Awal', Simplepreet Kaur1, Amandeep Singh²}

\begin{abstract}
${ }^{1}$ Department of Dermatology, Venereology and Leprology, Sri Guru Ram Das Institute of Medical Sciences and Research, Amritsar, Punjab, India, ${ }^{2}$ Department of Radiology, Sri Guru Ram Das Institute of Medical Sciences and Research, Amritsar, Punjab, India
\end{abstract}

Corresponding author: Dr. Guneet Awal, E-mail: guneetawal@gmail.com

\begin{abstract}
Stewart Bluefarb syndrome is a rare acroangiodermatitis which occurs due to presence of arteriovenous malformations. It presents at birth or during early childhood as an erythematous to violaceous plaques over the dorsum of foot or ankle. It's a benign condition but can mimic a malignant condition, Kaposi's sarcoma. Histopathological differentiation between these two conditions is important. Investigations like doppler ultrasound are required to establish the diagnosis. In long standing cases, complications like ulceration, bleeding and secondary infections can occur. Treatment includes surgical correction of underlying arteriovenous malformation.
\end{abstract}

Key words: Stewart Bluefarb syndrome; Acroangiodermatitis; Arteriovenous malformation; Kaposi's sarcoma

\section{INTRODUCTION}

Stewart Bluefarb syndrome is a variant of acroangiodermatitis, also known as Pseudo-Kaposi sarcoma. Acroangiodermatitis is an uncommon condition characterized by reactive proliferation of cutaneous blood vessels in response to chronic circulatory disturbance. It is often seen in association with various vascular anomalies such as venous insufficiency, arteriovenous shunts etc [1]. Stewart Bluefarb syndrome presents in young patients due to underlying arteriovenous malformation. It appears unilaterally, over the dorsum of foot, ankle or calf. Clinically, this condition presents as erythematous to violaceous, indurated plaques, usually located over lower extremities [2]. It may be associated with edema or hypertrophy of affected foot or limb. Although, it's a benign condition, it needs to be differentiated from a well known, imitating malignant condition, Kaposi's sarcoma. Due to rarity of this condition, we report a case of Stewart Bluefarb syndrome in a 25 year old female.

\section{CASE REPORT}

A 25 year old female patient presented to our dermatology outpatient department with complaints of swelling of second toe of right foot with presence of raised, violaceous lesions on the dorsum of same toe (Fig. 1). On enquiring further, patient revealed that these lesions are present since the age of 5 years and an increase in size of lesions was observed from last 4 years. There was history of swelling of affected toe and forefoot on walking. On examination, a single erythematous to violaceous, flat topped plaque of size approximately $6 \times 3 \mathrm{~cm}$ was present over the dorsum of second toe of right foot sparing the nail. It was surrounded by few small, discrete plaques of similar appearance extending upto proximal part of dorsum of foot. On further examination, girth of affected toe was more as compared to rest of the toes with multiple dilated tortous blood vessels radiating out from proximal end of affected toe. On palpation, plaques were compressible and soft in consistency, blanchable and non tender. Pulsations in

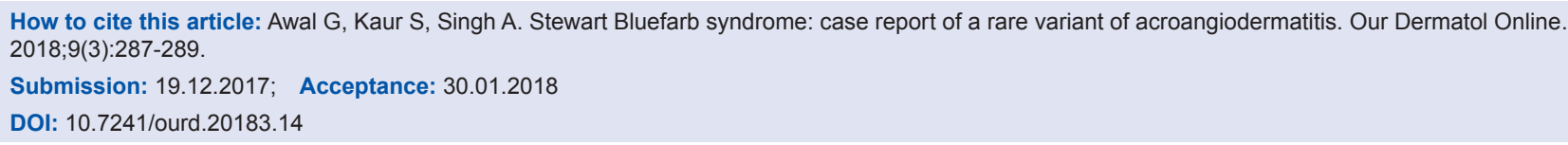


the affected toe were normal. Toe girth discrepancy was measured to be $2 \mathrm{~cm}$ and there was no toe length discrepancy. There was no audible bruit or palpable thrill. Routine investigatons including complete blood count, liver and renal function tests and urine complete examination were within normal limits. Enzyme linked immunosorbent assay (ELISA) for human immunodeficiency virus (HIV) was non reactive. No significant abnormality was detected on systemic examination. Arteriovenous doppler ultrasound (USG) revealed presence of high velocity monophasic arterialised flow beneath the plaque that suggested an arteriovenous malformation. Contrast enhanced magnetic resonance angiography revealed presence of dilated tortous blood vessels making a fistula beneath the plaque. Histopathological examination revealed an increased number of thick walled capillaries, present in a clustered pattern within thickened papillary dermis. These vessels were surrounded by mucin and sparse perivascular lymphocytic infiltrate. Moderate amount of hemosiderin deposits were seen around many of these vessels (Fig. 2). Dermoscopy revealed presence of blood filled lacunar spaces (Fig. 3). On the basis of history, clinical examination and investigations like doppler USG, magnetic resonance angiography and histopathology, diagnosis of Stewart Bluefarb syndrome was confirmed. Prior to the study, patient gave written consent to the examination and biopsy after having been informed about the procedure.

\section{DISCUSSION}

Acroangiodermatitis or Pseudo-Kaposi sarcoma is an uncommon angioproliferative disease that can simulate many other conditions such as Kaposi's sacroma, hemangioma, lymphangioma, basal cell carcinoma etc. In the present case, on the basis of clinical examination, differentials taken into consideration were Kaposi's sarcoma, tufted angioma, verrucous hemangioma and eccrine syringofibroadenoma. On the basis of investigations, all other conditions were ruled out and diagnosis of Stewart Bluefarb syndrome was established. Acroangiodermatitis was first described by Kopf and Gonzale. There are 4 variants of acroangiodermatitis namely, Stewart Bluefarb syndrome (associated with arteriovenous malformations), Mali type (associated with chronic venous insufficiency), Dermite ocre of Favre (associated with first pregnancy) and in chronic renal failure over hemodialysis shunt [3]. Stewart Bluefarb syndrome was

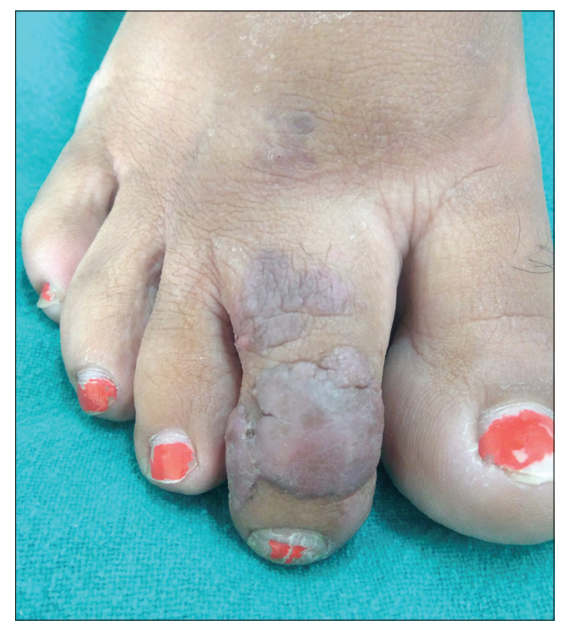

Figure 1: Violaceous plaque on dorsum of right foot second toe.

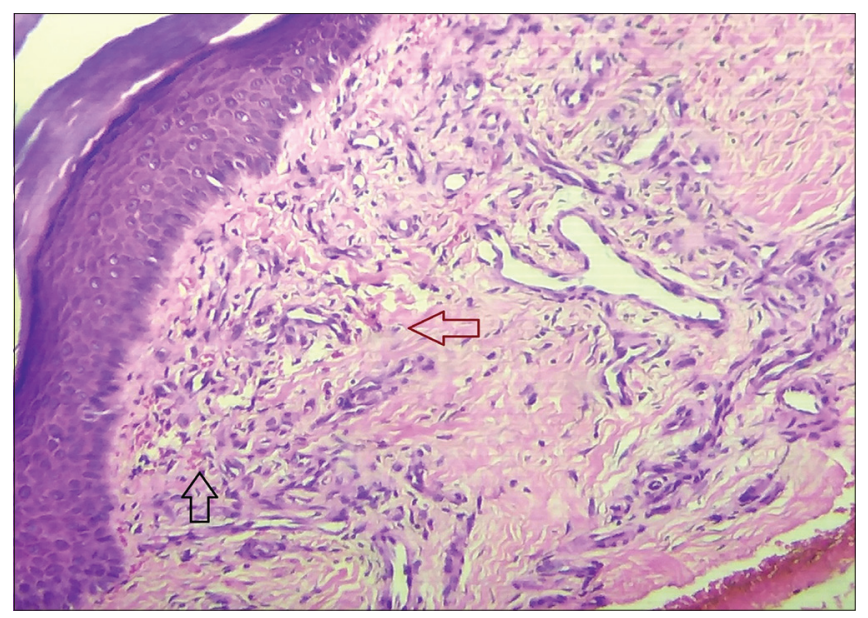

Figure 2: Histopathological picture showing proliferation of blood vessels in a cluster (red arrow) and presence of hemosiderin deposits (black arrow). (H\&E, 100X).

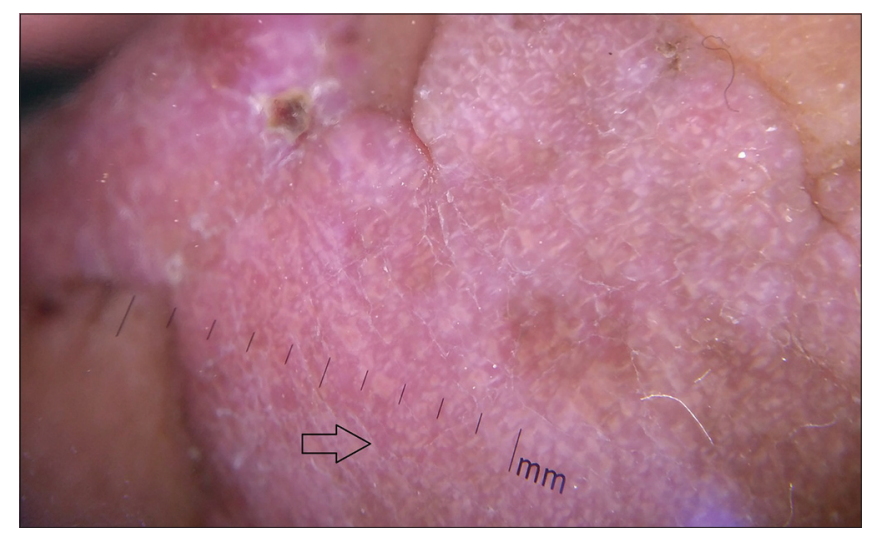

Figure 3: Dermoscopic picture showing blood filled lacunar spaces (black arrow).

described by Bluefarb and Adam as an arteriovenous malformation with angiodermatitis [4]. Underlying arteriovenous malformation causes abnormal oxygen and carbon dioxide perfusion that leads to distal 
ischemia. This ischemia is responsible for release of various endothelial proliferation growth factors causing hypertrophy and skin changes. This condition may occur at birth or during early childhood and clinically presents as soft, compressible, painful nodules or plaques, mostly located unilaterally on the dorsum of foot or ankle. It may also be associated with edema or hypertrophy of affected area. Stewart Bluefarb syndrome has been reported to be associated with other syndromes such as Klippel Trenaunay Weber syndrome [5]. Palpable thrill and audible bruit can be appreciated in some cases along with varicose veins. In the present case, hypertrophy of affected toe was observed but with absence of thrill or bruit. Magnetic resonance angiography revealing underlying arteriovenous malformation, acts as a diagnostic tool. In these cases, histopathological examination of affected skin should be done in order to differentiate it from a known malignant condition, Kaposi's sarcoma. On histopathology, in Kaposi's sarcoma, vessels with slits, Cluster of Differentiation 34 (CD34) positive spindle shaped and atypical cells proliferation is observed whereas in Stewart Bluefarb syndrome, no atypical cells and vascular slits are seen and cells are CD34 negative. In our case, CD34 immunohistochemical staining was not performed but other histopathological features such as absence of atypical cells and spindle shaped cells, absence of vascular slits, helped in establishing the diagnosis of Stewart Bluefarb syndrome. There are chances of misdiagnosis of this syndrome if relevant investigations are not performed and complications like ulceration, bleeding and secondary infections can occur. Hence, early diagnosis and management is important in such cases. Surgical correction of underlying arteriovenous malformation is the mainstay of treatment [6]. In the present case, patient was counselled regarding surgical correction of arteriovenous malformation.

\section{CONCLUSION}

Stewart Bluefarb syndrome is an uncommon variant of acroangiodermatitis which appears due to arteriovenous malformation beneath the affected area. This condition closely resembles Kaposi's sarcoma, hence histopathological differentiation is required. For early diagnosis, investigations like ultrasound doppler or magnetic resonance angiography should be performed and then, surgical correction of underlying malformation should be planned.

\section{CONSENT}

The examination of the patient was conducted according to the Declaration of Helsinki principles.

\section{REFERENCES}

1. Singh SK, Manchanda K. Acroangiodermatitis (Pseudo-Kaposi sarcoma). Indian Dermatol Online J. 2014;5:323-5.

2. Pimentel MI, Cuzzi T, Azeredo-Coutinho RB, Vasconcellos Éde C, Benzi TS, Carvalho LM. Acroangiodermatitis (pseudo-Kaposi sarcoma): a rarely-recognized condition. A case on the plantar aspect of the foot associated with chronic venous insufficiency. An Bras Dermatol. 2011;86:S1.

3. Ghia DH, Nayak CS, Madke BS, Gadkari RP. Stewart-Bluefarb acroangiodermatitis in a case of Parkes-Weber syndrome. Indian J Dermatol. 2014;59:406-8.

4. Jindal R, Dipankar D, Dogra S, Saikia UN, Kanwar AJ. Acroangiodermatitis of Mali in a patient with congenital myopathy. Dermatol Online J. 2010;16:4.

5. Mehta AA, Pereira RR, Nayak CS, Dhurat RS. Acroangiodermatitis of Mali. A rare vascular phenomenon. Indian J Dermatol Venereol Leprol. 2010;76:553-6.

6. Ben Rejeb S, Chelly I, Zhani A, Chellly B, Haouet S, Mokni M, et al. Acquired elastotic hemangioma: A diagnosis to keep in mind. Our Dermatol Online. 2017;8:443-5.

Copyright by Guneet Awal, et al. This is an open access article distributed under the terms of the Creative Commons Attribution License, which permits unrestricted use, distribution, and reproduction in any medium, provided the original author and source are credited.

Source of Support: Nil, Conflict of Interest: None declared. 